\title{
ANALYSIS OF THE PRINCIPAL CONSTITUENTS OF SOLID EARTH TIDES ESTIMATED WITH GRAVIMETRIC AND GNSS DATA IN MANAUS AND BRASÍLIA
}

\author{
Mário A. de Abreu ${ }^{1}$, Giuliano S. Marotta ${ }^{1}$, Lavoisiane Ferreira', Denizar Blitzkow², \\ Ana C. O. C. de Matos ${ }^{2}$ and João Francisco Galera Monico ${ }^{3}$
}

\begin{abstract}
Solid Earth tide is the periodic displacement due to the tidal force. This effect is present in all geodesic and geophysical observations and should be eliminated when high accuracy surveying is required. It is necessary to determine the amplitudes and phases of the harmonic constituents to estimate the terrestrial tide effect magnitude. This article presents a methodology for estimating and analyzing the amplitudes and phases of the solid Earth tide principal constituents from gravimetric/GNSS observations. The methodology was applied to data collected in the Manaus/AM and Brasília/DF stations, Brazil, to determine the amplitude and phase values for the long period, monthly, diurnal and semidiurnal constituents, besides determining the time required for the convergence of the estimated constituent values. The estimated amplitude and phase values, using gravimetric data, converged between the $2^{\text {nd }}$ and $6^{\text {th }}$ months of the time series. For the positioning observations, the constituents values converged between the $2^{\text {nd }}$ and $17^{\text {th }}$ months of the data series, except for the long period constituent, which requires a longer time series to obtain satisfactory values for both methods. The results show that the solid Earth tide constituents were better estimated by the gravimetric data compared to the positioning data considering the series analyzed.
\end{abstract}

Keywords: gravimetry, GNSS, solid Earth tide, tidal constituents.

RESUMO. Maré terrestre é o deslocamento periódico decorrente da força de maré. Este é um efeito que deve ser eliminado quando se deseja realizar levantamentos nos quais é necessária alta acurácia tanto em observações geodésicas quanto geofísicas. Para estimar o efeito de maré terrestre deve-se determinar as amplitudes e fases de suas componentes harmônicas. Este artigo apresenta uma metodologia para a estimativa das amplitudes e fases das principais componentes de maré terrestre, a partir de observações gravimétricas/GNSS. A metodologia foi aplicada a dados coletados em estações instaladas em Manaus/AM e Brasília/DF, Brasil, resultando na determinação dos valores de amplitude e fase para componentes de longo período, mensais, diurnas e semidiurnas, além da análise da convergência dos valores estimados para estas componentes. As amplitudes e fases calculadas, utilizando dados gravimétricos, convergiram entre $02^{\circ}$ e $06^{\circ}$ mês analisados, enquanto para os dados de posicionamento a convergência ocorreu entre $02^{\circ}$ e $017^{\circ}$ mês observado, com exceção da componente de longo período, que não pôde ser determinada em ambos os métodos. Para o período analisado, as componentes de maré terrestre foram melhor estimadas utilizando dados gravimétricos, se comparadas aos resultados obtidos com dados de posicionamento.

Palavras-chave: gravimetria, GNSS, maré terrestre, componentes de maré

\footnotetext{
1'Universidade de Brasília, Observatório Sismológico, Campus Universitário Darcy Ribeiro, SG 13, Asa Norte, 70910-900, Brasília, DF, Brazil. Phone: +55(61) $3107-0912$ -E-mails: mario.abreu@ibge.gov.br, marotta@unb.br, lavoisiane@outlook.com

${ }^{2}$ Universidade de São Paulo, Escola Politécnica, Departamento de Engenharia de Transportes, Prédio da Engenharia Civil, Cidade Universitária, Av. Prof. Almeida Prado, travessa 2, no. 83, 05424-970, São Paulo, SP, Brazil. Phone: +55(11) 3091-5501 Fax: +55(11) 3091-5716 - E-mails: dblitzko@usp.br, acocmatos@gmail.com ${ }^{3}$ Universidade Estadual Paulista Júlio de Mesquita Filho, Faculdade de Ciências e Tecnologia, Departamento de Cartografia, Centro Educacional, Rua Roberto Simonsen, 305, 19060-900, Presidente Prudente, SP, Brazil. Phone: +55(18) 3229-5511 Fax: +55(18) 3229-5353 - E-mail: galera.monico@unesp.br
} 


\section{INTRODUCTION}

Solid Earth tide is the phenomenon resulting from the tidal force, through the Earth crust movement, which can be observed by the periodic displacement measured on the Earth surface. The tidal force is understood as the difference between the Earth mass center and surface forces due to the gravitational effect.

Solid Earth tide studies started in 1863, according Ekman (1993), when William Thomson introduced the idea that the Earth is not a completely rigid body, but subject to viscoelastic deformations, especially due to the lunisolar attraction. Now a day, the solid Earth tide studies have become more important due to the development of geophysical and geodetic methods, and new data observation techniques, which improved measurement accuracy so that previously neglected effects must be corrected now.

Currently, the global models used to reduce the effect of solid Earth tide were developed using gravity field observations and displacements measured on the Earth surface. Therefore, more refined and accurate models require densifying the observations and, for this purpose, gravity meters and GNSS receivers prove to be very useful.

Superconductor gravimeters are considered the most accurate technique for estimating gravity variations caused by solid Earth tides, but relative gPhone gravimeters are also effective for observing the phenomenon. Based on gravimetric surveys, several studies were conducted to understand better the solid Earth tide effect, among which Baker \& Bos (2003); Arnoso et al. (2011); Miranda et al. (2015); Middlemiss et al. (2016) and Benedito et al. (2017).

In Geodesy, since the 1980s, Very Long Baseline Interferometry (VLBI) observations have been used to analyze solid Earth tide effects, as seen in Krásná et al. (2012). More recently, GNSS has been presented as a useful tool to study the crustal movement since it allows continuous observations, has good accuracy, besides the large number of stations distributed on the Earth's surface. When using GNSS to monitoring solid Earth tide, it is necessary to take into account the errors related to the satellites, receivers and signal propagation, besides the deformational effects related to the oceanic, atmospheric and hydrological loads and the pole movement as well. These errors and effects must be analyzed and removed to obtain a reliable modeling for this phenomenon. Among the several works using GNSS to study the solid Earth tide, Watson et al. (2006); Ito et al. (2009); Yuan (2009); Yuan et al. (2013) and Alihan et al. (2017) are highlighted.
Understanding the deformations resulting from the solid Earth tides is important because this effect is present in all geophysical and geodetic observations while having a significant impact on the Earth geological processes. In this sense, studies by Kasahara (2002); Cochran et al. (2004); Chen et al. (2012) and Varga \& Grafarend (2019) demonstrated that tides could contribute to Earthquakes and volcanism.

The objective of this study is to estimate the principal solid Earth tide constituents using gravimetric and positioning observations conducted in two stations in Manaus and Brasília, thus contributing to improve the knowledge for modeling this important effect since the solid Earth tide modeling is still poorly understood, with very limited application in Brazil.

\section{METHODOLOGY TO DETERMINING THE SOLID EARTH TIDE CONSTITUENTS}

To determine the solid Earth tide constituents, the data must be treated to decrease the uncertainty inherent to the identification and estimation of these constituents. For this, the gravimetric and positioning data must be edited, corrected and processed.

\section{Gravimetric Data Editing, Correcting and Processing}

The flowchart in Figure 1 shows the sequence followed for editing, correcting and processing the gravity variation data measured continuously by a relative gravimeter.

The data editing consists of identifying and removing the spikes from the time series so that only the measured periodic signal remains. From the analysis of the time series, the spikes are identified and removed. Only the most discrepant spurious points need to be eliminated, and this can be done visually. These removed spikes are usually related to recording problems or seismic movements recorded by the equipment. The purpose of spike removal is to maintain only the periodic signal measured by the gravimeter, to improve the accuracy when determining the solid Earth tide constituents. However, the removed spikes leave gaps where the missing data were in the series as seen in Figure 2.

Subsequently, the data were corrected for the gravimeter level (Melchior, 2008), atmospheric pressure (Boy et al., 2002) and barometric compensation (Warburton \& Goodkind, 1977), thus minimizing the atmospheric effects recorded by the gravimeter. Other important corrections to be considered are related to the pole movement effect (Jekeli, 2012) and ocean load (Farrell, 1972).

The steps and shift (instrumental displacement) must also be corrected. 


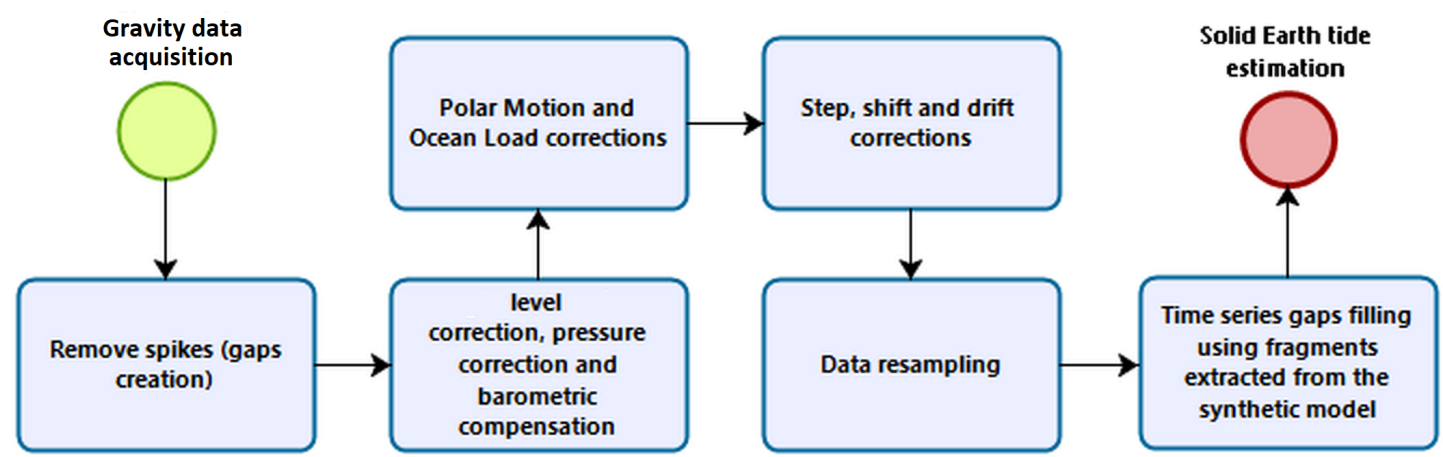

Figure 1 - Gravity data processing sequence.
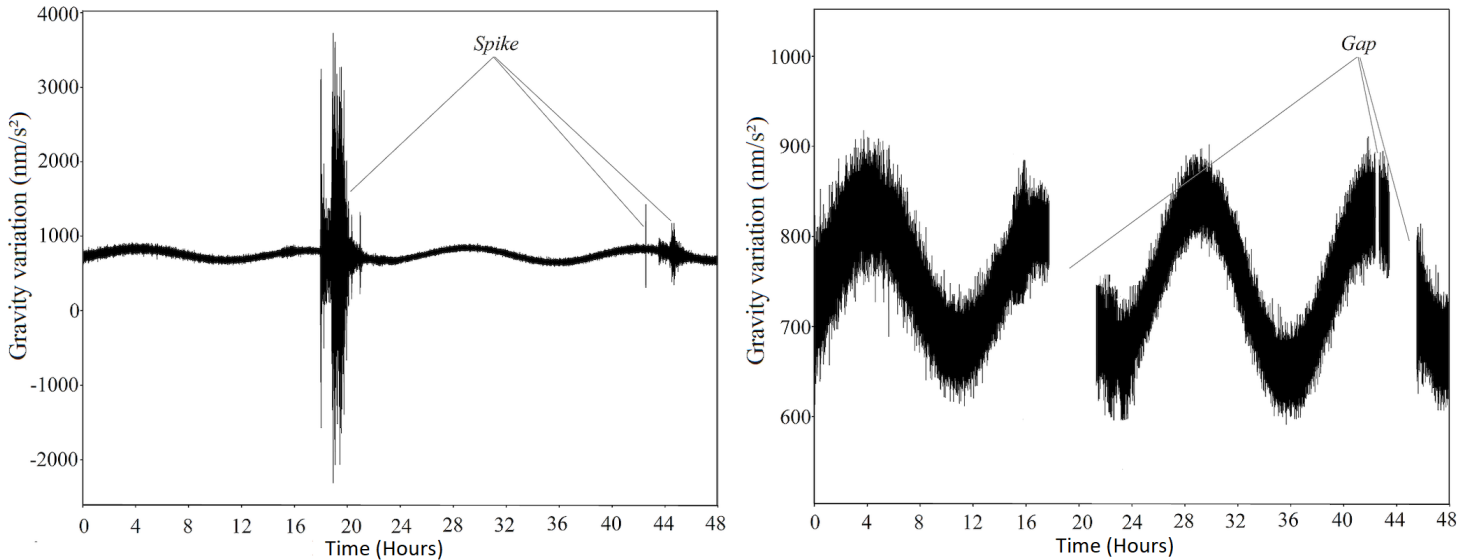

Figure 2 - The graph on the left shows the spikes in the raw signal data extracted from a gravimeter. The graph on the right shows the same signal, after eliminating the spikes, and the resulting gaps.
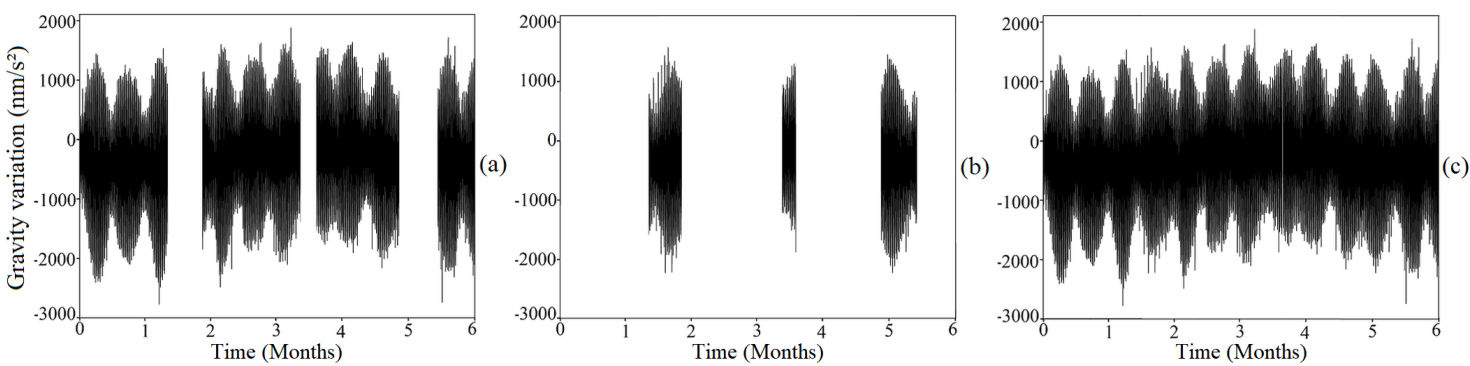

Figure 3 - (a) graph shows the corrected signal with gaps; (b) graph shows the sections extracted from the theoretical model of the solid Earth tide to fill in the gaps; and (c) the complete corrected signal, resulting from the sum of the signals in (a) and (b).

In addition, it is important to correct the drift using a polynomial equation that fits the observed data. To correct these instrumental errors, the parameters of the recommended functional model can be obtained by the LSM (least squares method):

$$
F(t)=a+b t+c t^{2}+\sum_{i=1}^{n} d H(t)_{i}
$$

$a$ is the shift (instrumental displacement); $t$ is the time; $b$ and $c$ are the drift coefficients; $d$ is the step; and $H$ is the step function.

To free the time series from the discontinuities, the gaps can be filled using fragments of the theoretical solid Earth tide model. The information at the starting and ending sections of each gap left by the spike removal is used to extract the data using the theoretical model of solid Earth tide to fill in the gap, resulting in a 
non-disruptive time series. The result of extracting the gaps from the theoretical signal and the filling in of the observed signal is shown in Figure 3.

It is important to fill in the gaps of the observed data series using the synthetic model as a reference since interpolation methods would not allow the complete reconstruction of the solid Earth tide signal while the theoretical model calculates a signal closer to the observed one.

The gap filling is necessary because lack of data in the time series can be interpreted as the beginning of a new observation sequence during processing, resulting in a greater uncertainty associated with the results. A continuous time series (Fig. 3c), without gaps, must be used for determining the constituents more accurately.

To estimate tidal constituents, it is important to define which of the various constituents to determine. According to Petit \& Luzum (2010), tides have 11 principal constituents, shown in Table 1.

$i$ is Doodson number, $t$ the mean solar time, $\tau$ the mean lunar time, $s$ variation of the moon declination, $p$ the revolution of the mean lunar perigee, and $h$ one-year period (365.25 days).

After defining the constituents to be estimated, it is convenient to analyze the spectrum of the observed signal as to identify the frequency intervals (Fig. 4) where the desired constituents are located.

The frequency intervals identified in the spectrum can be entered in the processing and used to determine the amplitude factor and the phase difference of the solid Earth tide harmonic constituents.

The tidal constituents can be determined using the tidal generating potential presented by Hartmann \& Wenzel (1995):

$$
\begin{aligned}
V(t)= & \sum_{l=1}^{l_{\max }} \sum_{m=0}^{l}\left(\frac{r}{a}\right)^{l} P_{l m}^{\prime} \cos (\theta) \sum_{i}\left[C_{i}^{l m}(t) \cos \left(\alpha_{i}(t)\right)\right. \\
& \left.+S_{i}^{l m}(t) \sin \left(\alpha_{i}(t)\right)\right]
\end{aligned}
$$

Where $C_{i}^{l m}(t)$ and $S_{i}^{l m}(t)$ are the time-dependent tidal potential coefficients; $P_{l m}^{\prime}$ are the fully normalized Legendre functions; $a \mathrm{~s}$ the semi major axis of the reference ellipsoid; $t$ $s$ the time from J2000 in Julian centuries; $l=1, \ldots, l_{\max }=6$ and $m$ are the degree and order of the series, respectively; $r$, $\theta$ and $\lambda$ are the geocentric spherical coordinates; and $\alpha_{i}(t)=$ $m \lambda+\sum_{j=1}^{11} k_{i j} \arg _{j}(t)$ are the astronomical arguments.

\section{Positioning Data Editing, Correcting and Processing}

The positioning dataset collected by the GNSS stations was edited, standardized and processed using the methodology outlined in Figure 5 and explained below.

First, the GNSS data were checked for file integrity to detect any flaws that could affect processing using specific software, such as the TEQC (Translation, Editing, and Quality Check), described by Estey \& Meertens (1999).

he GNSS coordinates can be determined by applying the kinematic mode (Monico, 2007) of the PPP (Precise Point Positioning) method (Zumberge et al., 1997). Also, processing should use precise orbits, as well as other corrections such as satellites clocks, antenna phase center, tropospheric and ionospheric effects, pole movement, and oceanic load for obtaining coordinates that are more precise. The solution is static, at first, to solve the ambiguities and determine the tropospheric correction parameters. After solving the ambiguities, the positioning in the kinematic mode is performed to improve positioning quality.

The solid Earth tide constituents are determined from the calculated latitude $(\phi)$, longitude $(\lambda)$ and geometric altitude (h) coordinates. It is important to define the constituents to be estimated. Table 1, shown above, shows the 11 major tidal constituents, and Solid Earth tide constituents can be estimated from the astronomical arguments.

\section{STUDY AREA}

The used data were collected in the gravimetric and GNSS stations located in Manaus and Brasília, Brazil.

In Manaus, the gravimeter and the GNSS receiver were installed at CENSIPAM (Operational and Management Center of the Amazon Protection System), shown in Figure 6. Manaus is located at $92 \mathrm{~m}$ average altitude, having $2300 \mathrm{~mm}$ average annual rainfall, with very well defined rain and dry seasons. It is located in the Amazon basin, a region of great scientific interest due to the global environmental and climatic relevance and biodiversity (Costa et al., 2012). Additionally, this region lacks gravimetric data due to the difficult access for field surveys.

In Brasillia, the gravimeter was installed at Seismological Observatory of the Universidade de Brasilia (UnB), and the GNSS receiver was located in the IBGE Ecological Reserve, as seen in Figure 6. Brasilia is located in the central Brazilian plateau, at about $1170 \mathrm{~m}$ average altitude while the $1540 \mathrm{~mm}$ average annual rainfall is $35 \%$ less than in Manaus, it is also characterized by very well defined rain and dry periods. 
Table 1 - Principal tidal constituents (adapted from Melchior, 1983).

\begin{tabular}{|c|c|c|c|c|}
\hline Name & $i$ & Argument & Frequency ( $\left.{ }^{\circ} / \mathrm{h}\right)$ & Source \\
\hline \multicolumn{5}{|c|}{ Long term constituents } \\
\hline $\mathbf{S}_{s a}$ & 057.555 & $2 h$ & 0.082137 & Solar semiannual \\
\hline $\mathbf{M}_{m}$ & 065.455 & $s p$ & 0.544375 & Lunar monthly \\
\hline $\mathbf{M}_{f}$ & 075.555 & $2 s$ & 1.098033 & Lunisolar fortnightly \\
\hline \multicolumn{5}{|c|}{ Diurnal constituents } \\
\hline $\mathbf{Q}_{1}$ & 135.655 & $(\tau s)(s p)$ & 13.398661 & Larger lunar elliptic \\
\hline $\mathbf{O}_{1}$ & 145.555 & $\tau s$ & 13.943036 & Lunar diurnal \\
\hline $\mathbf{P}_{1}$ & 163.555 & $\tau h$ & 14.958931 & Solar diurnal \\
\hline $\mathbf{K}_{1}$ & 165.555 & $\tau+s$ & 15.041069 & Lunisolar diurnal \\
\hline \multicolumn{5}{|c|}{ Semidiurnal constituents } \\
\hline $\mathbf{N}_{2}$ & 245.655 & $2 \tau(s p)$ & 28.439730 & Larger lunar elliptic \\
\hline $\mathbf{M}_{2}$ & 255.555 & $2 \tau$ & 28.984104 & Principal lunar \\
\hline $\mathbf{S}_{2}$ & 273.555 & $2 t$ & 30.000000 & Principal solar \\
\hline $\mathbf{K}_{2}$ & 275.555 & $2(\tau+s)$ & 30.082137 & Lunisolar semidiurnal \\
\hline
\end{tabular}

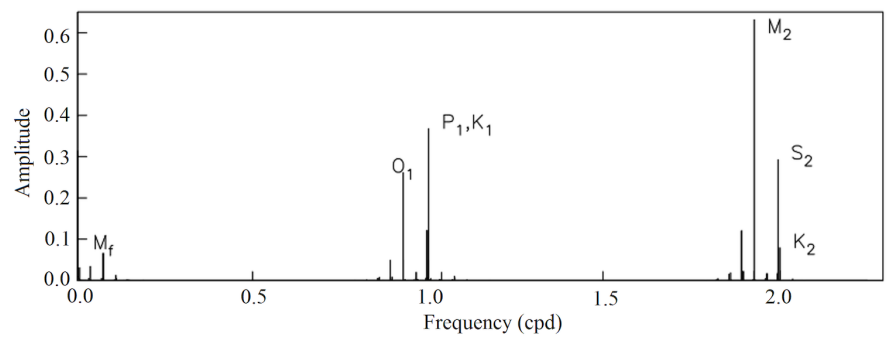

Figure 4 - Frequency spectrum expanded to degree 2, showing some tidal constituents (source: Agnew, 2010).

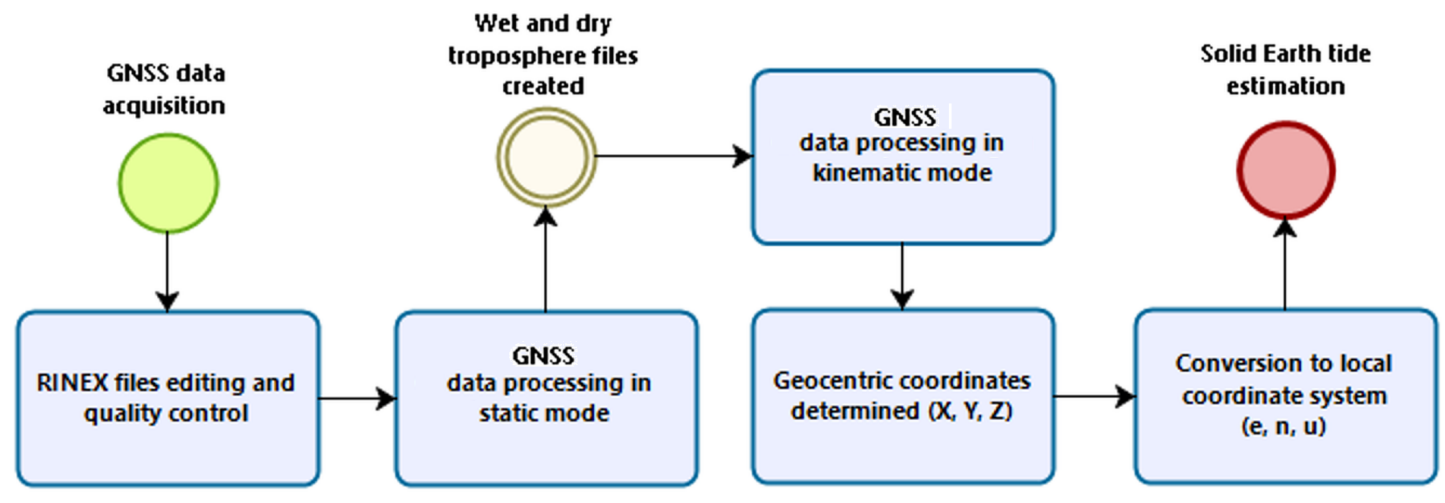

Figure $\mathbf{5}$ - Flowchart of the positioning data processing steps. 


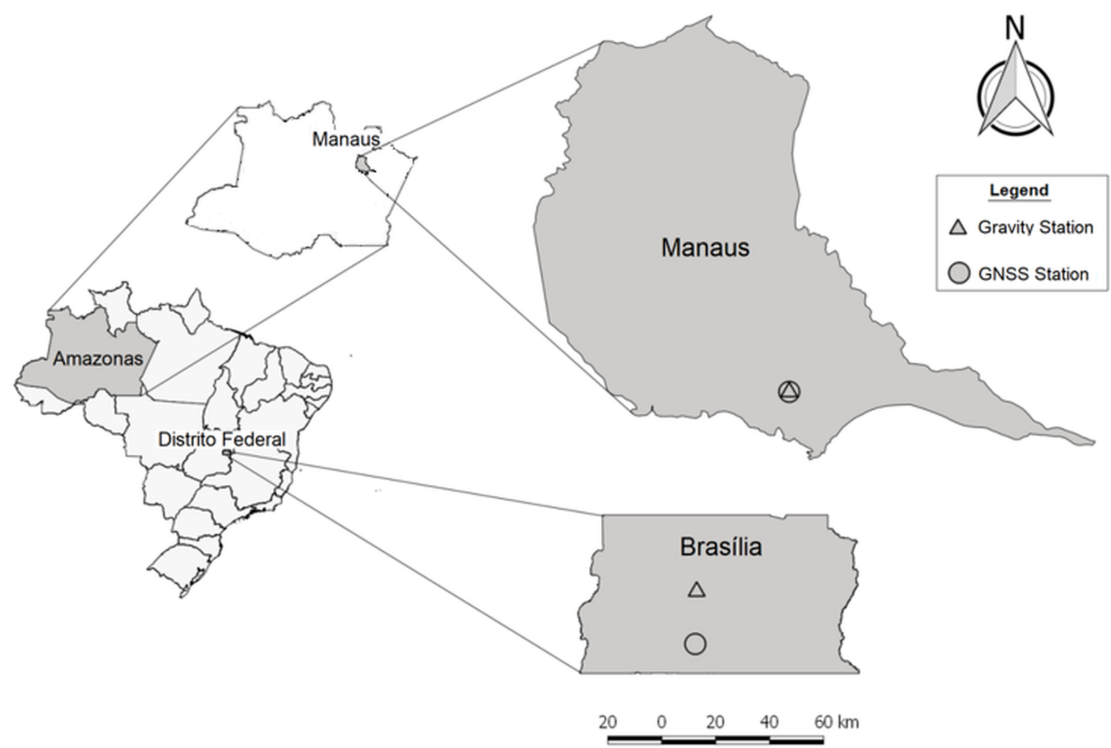

Figure 6 - Map showing the gravimetric and GNSS stations in Manaus and Brasilia.

Another important factor for choosing the sites to be studied was the fact that both cities had available time series longer than one year, in addition to active GNSS stations belonging to SIRGAS-CON (Geocentric Reference System for the Americas - Continuous Monitoring) and RBMC (Brazilian Network for Continuous Monitoring of GNSS Systems).

\section{DATA ACQUISITION}

The relevant information regarding the acquisition of gravimetric and GNSS data follows.

\section{Gravity Data}

The used gravimetric data were obtained by a gPhone gravimeter manufactured by the Micro-g LaCoste, with $0.1 \mu \mathrm{Gal}$ resolution and $1 \mu \mathrm{Gal}$ accuracy (LaCoste, 2018), constructed to allow a low instrumental drift ( $\approx 1.5 \mathrm{mGal} / \mathrm{month}$ ) and recommended for observing periodic signals and, therefore, indicated for studying solid Earth tides.

Both gravimeters were installed on a concrete pillar, isolated from the building, allowing reasonable stability and minimizing noise. The calibration of the gravimeters was done before the beginning of the acquisition of the data and, after, the verification of the gravimetric level was done frequently.

The gravimetric data were generated daily at $1 \mathrm{~Hz}$ sampling rate. The gravimeter records more than four channels but only four were used, as follows: continuous gravity measurement,
gPhone level, atmospheric pressure corrections, and barometric compensation, all expressed in $\mu \mathrm{Gal}$.

It is noteworthy that the gravity measurements analyzed in this work were not automatically corrected for any effect.

\section{GNSS Data}

The used positioning data were collected in two active GNSS stations, NAUS (installed in 2005) and BRAZ (in 1995) stations. Both stations currently use a Trimble GNSS receiver (model NetR9) connected to a Zephyr Geodetic Model II antenna that enables tracking the GPS, GLONASS, Galileo, and Beidou systems. This equipment static positioning accuracy is $\sim 3 \mathrm{~mm}$ and $3.5 \mathrm{~mm}$ for the horizontal and vertical components, respectively.

The two stations have the data available free of charge through the IBGE (Brazilian Institute of Geography Foundation and Statistics) site.

The GNSS data were stored daily at a 15-second sampling rate $(\approx 0.067 \mathrm{~Hz})$ per record in the RINEX format (Receiver Independent Exchange Format).

\section{DETERMINING SOLID EARTH TIDE CONSTITUENTS}

The procedures for data editing and processing to determine solid Earth tide constituents using gravimetric and GNSS observations are shown in the sequence. 
The procedures were performed on the historical data of both time series covering 21 (from 01/26/2016 to 01/11/2017) and 18 (from 04/25/2016 to 11/11/2017) months in Manaus and Brasília, respectively.

\section{Determining Solid Earth Tide Constituents using Gravimetric Observations}

Data preparation for determining the solid Earth tide constituents using gravimetric data obtained by gPhone followed the methodology described in section "Gravimetric Data Editing, Correcting and Processing".

Thus, the first step consisted of removing the spikes of the time series. Subsequently, the data were corrected using information from the gravimeter level, atmospheric pressure, and barometric compensation.

The datasets were also corrected for the pole movement provided by the Paris Observatory and the ocean load generated on the Onsala Space Observatory (OSO) site. The ocean load chosen for this work was the FES2004 (Finite Element Solution 2004), recommended by Petit \& Luzum (2010), which takes into account the 11 principal harmonic constituents with their respective amplitudes and phases.

A routine developed in MATLAB was used for the step, shift and drift corrections shown in Eq. (1).

Following the corrections, the data that originally had a one-second sample rate was re-sampled for one minute, using a low-pass filter with a cut-off frequency of 720 cycles per day (Kang et al., 2011), applied to a 480-point moving window, equivalent to 16 hours of observation. Using this window in the data re-sampling allows the difference between the observed and the re-recorded tide frequencies be less than $0.05 \%$ (Van Camp \& Vauterin, 2005).

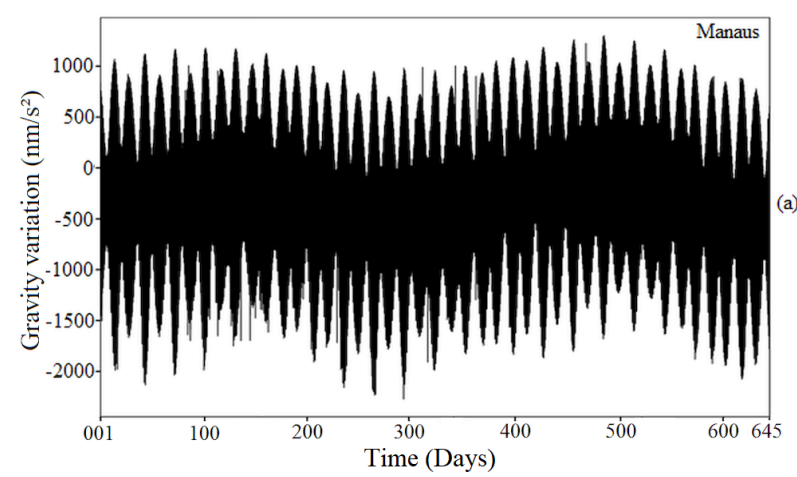

The last step of the time series preparation was to remove the gaps from the theoretical solid Earth tide model using a new routine developed in MATLAB.

The signals of the corrected time series are shown in Figure 7.

To estimate the solid Earth tide constituents in this work, we used the 11 principal tidal constituents defined by Petit \& Luzum (2010) as shown in Table 1.

The tide potential catalog of Hartmann \& Wenzel (1995), computing 12395 tidal waves and totaling 19300 adjusted parameters, was used for calculating the solid Earth tide constituents.

The methodology described in "Gravimetric Data Editing, Correcting and Processing" indicated that the intervals of the tide constituents to be determined were identified by analyzing the spectrum of gravity signal variation of both stations, as seen in Figures 8 and 9 . The long period constituent $\left(S_{s a}\right)$ could not be accurately identified and, therefore, it is not shown in the charts.

The intervals identified in the spectrum were inserted in the processing and used to determine the harmonic constituents of solid Earth tide.

No filter was used in the processing of the constituents since the filter could affect the calculated frequencies, by minimizing or eliminating relevant variations that might be analyzed.

Firstly, the processing used the data covering one month only, and then another month was added, followed by another month resulting in the processing of three months, and so on until the full-time data series was processed. This method was used to analyze the convergence of the computed values of amplitude, phase and their respective deviations over time.

Figures 10, 11, 12 and 13 show the results obtained after the processing of the 11 principal tide constituents. It should be

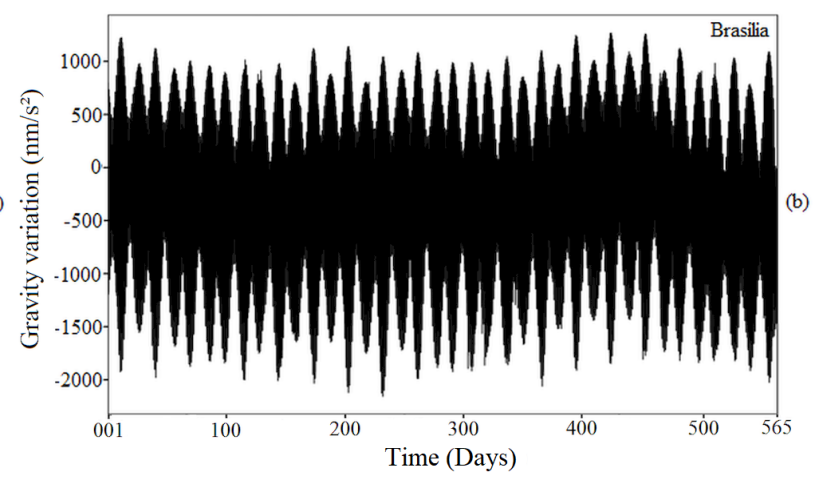

Figure 7 - Corrected time series showing the Manaus station data on the left and the Brasilia station data on the right. 
noted that the graphs were not normalized to allow visualizing the variability of all the constituents.

The Figures 10 to 13 show the amplitude factor, phase difference, and their respective uncertainties estimated for the long period $\left(S_{s a}\right)$, monthly $\left(M_{m}\right.$ and $\left.M_{f}\right)$, diurnal $\left(Q_{1}, O_{1}, P_{1}\right.$, and $\left.K_{1}\right)$ and semidiurnal $\left(N_{2}, M_{2}, S_{2}\right.$ and $\left.K_{2}\right)$ constituents for the time data series of both stations.

The analysis of Figures 10, 11, 12 and 13 allow the following considerations:

- The results for the long-term constituent $S_{s a}$ (Fig. 10) were not satisfactory since it was not possible to determine the values for both stations. This result is because this constituent requires a time data series covering a longer period to be accurately determined;

- The monthly constituents $M_{m}$ and $M_{f}$ (Fig. 11), the amplitude factor and the RMSE begin converging after 3 months and 5 months in the Manaus and Brasilia stations, respectively. The analysis of the phase difference graphs and their uncertainties shows that data convergence started from the $6^{\text {th }}$ and $8^{\text {th }}$ months in the Manaus and Brasília stations, respectively.

- Figure 12 shows that the diurnal constituents $\left(Q_{1}, O_{1}\right.$, $P_{1}$, and $K_{1}$ ) begin the convergence of the amplitude factor from the $2^{\text {nd }}$ month, which was similar for both stations.
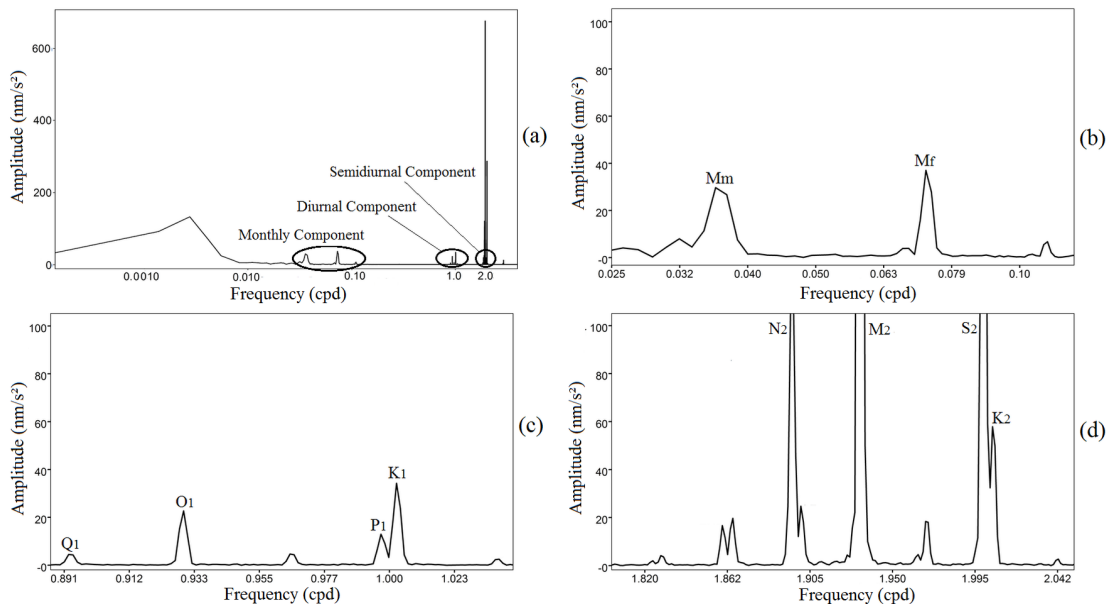

Figure 8 - Spectrum of the harmonic constituents of Manaus station. (a) shows the complete spectrum; (b), (c) and (d) show respectively the amplified spectrum only for the monthly, diurnal and semidiurnal constituents.
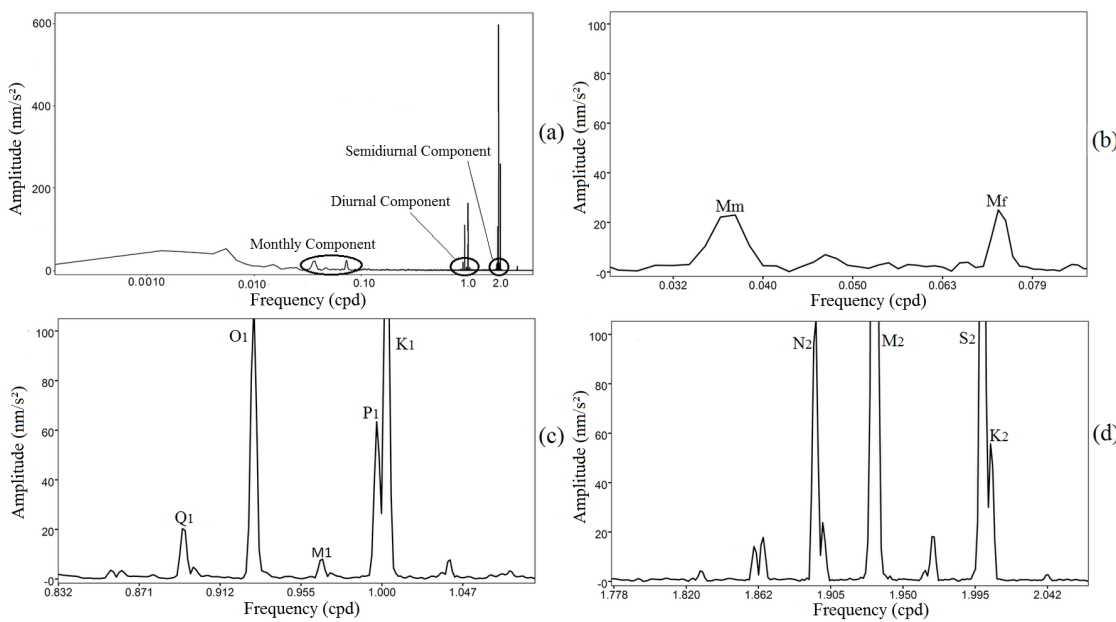

Figure 9 - Spectrum of the harmonic constituents of Brasilia station. (a) shows the complete spectrum; (b), (c) and (d) show respectively the amplified spectrum only for the monthly, diurnal and semidiurnal constituents. 

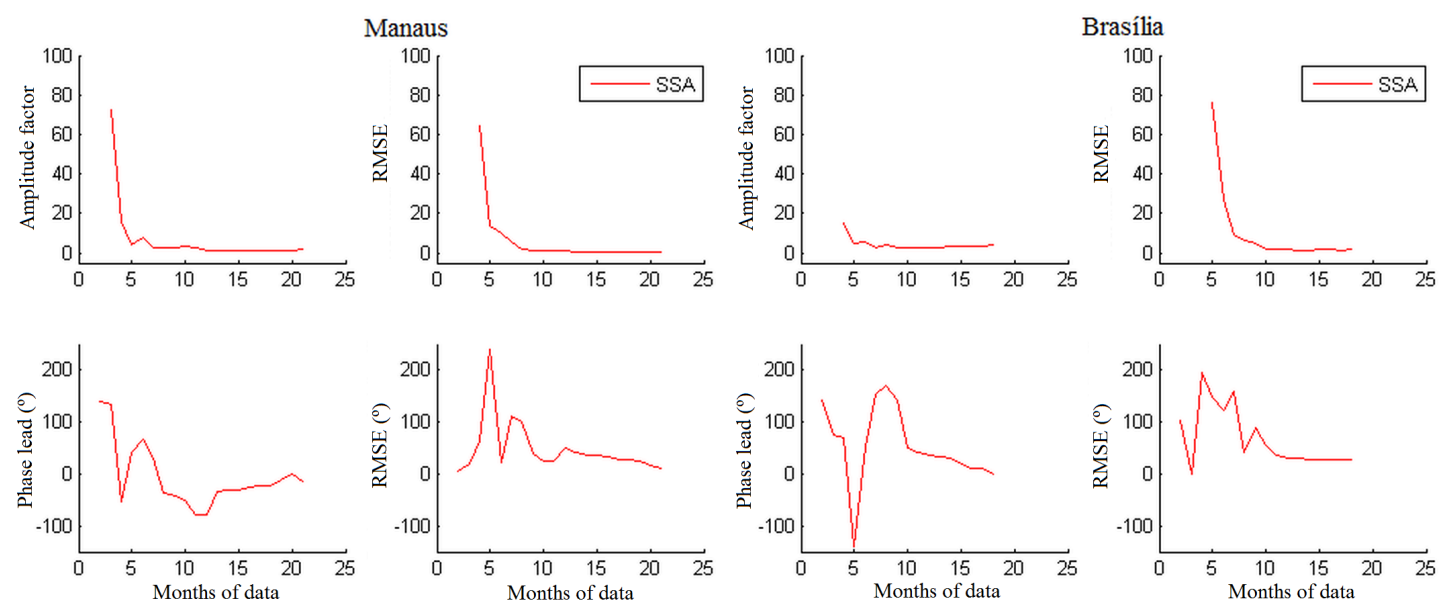

Figure 10 - Amplitude factor, phase difference, and respective root mean squared errors (RMSE) estimated for the long period $\left(S_{s a}\right)$ constituent of the Manaus (left) and Brasília (right) stations.
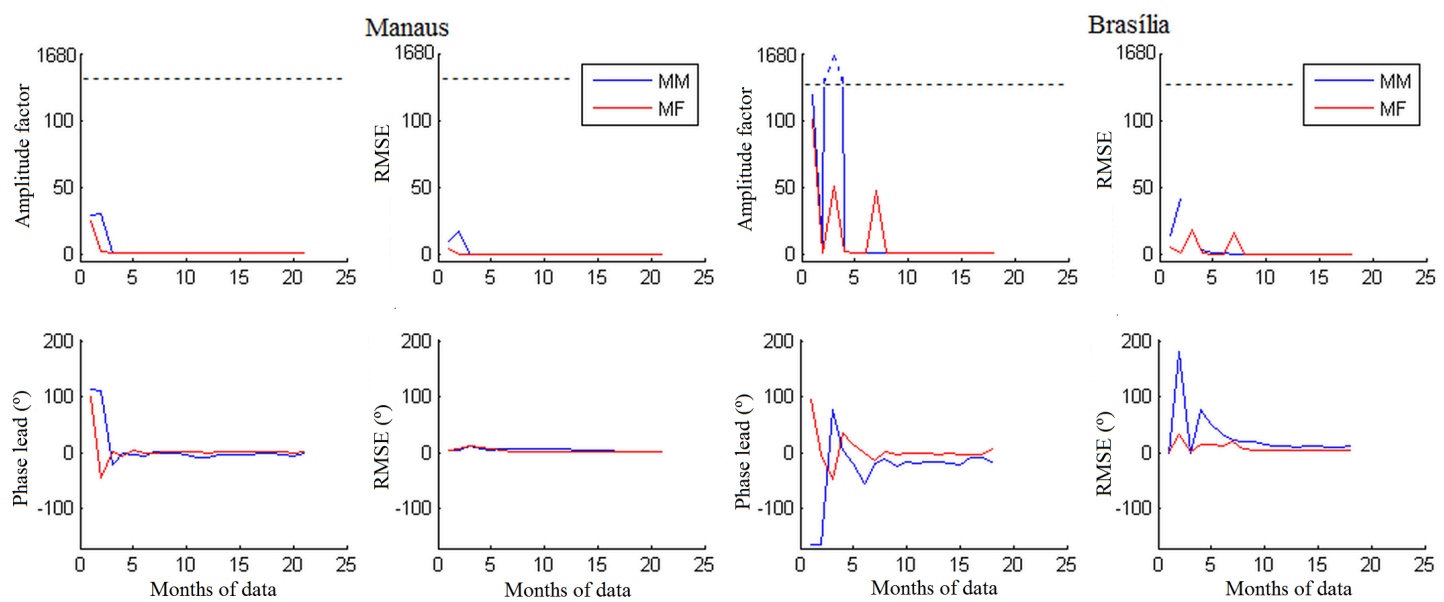

Figure 11 - Amplitude factor, phase difference, and respective RMSE estimated for the monthly $\left(M_{m}\right.$ and $\left.M_{f}\right)$ constituents of the Manaus (left) and Brasilia (right) stations. Dotted lines show the change of scale on figure to represent amplitude factor and phase difference.
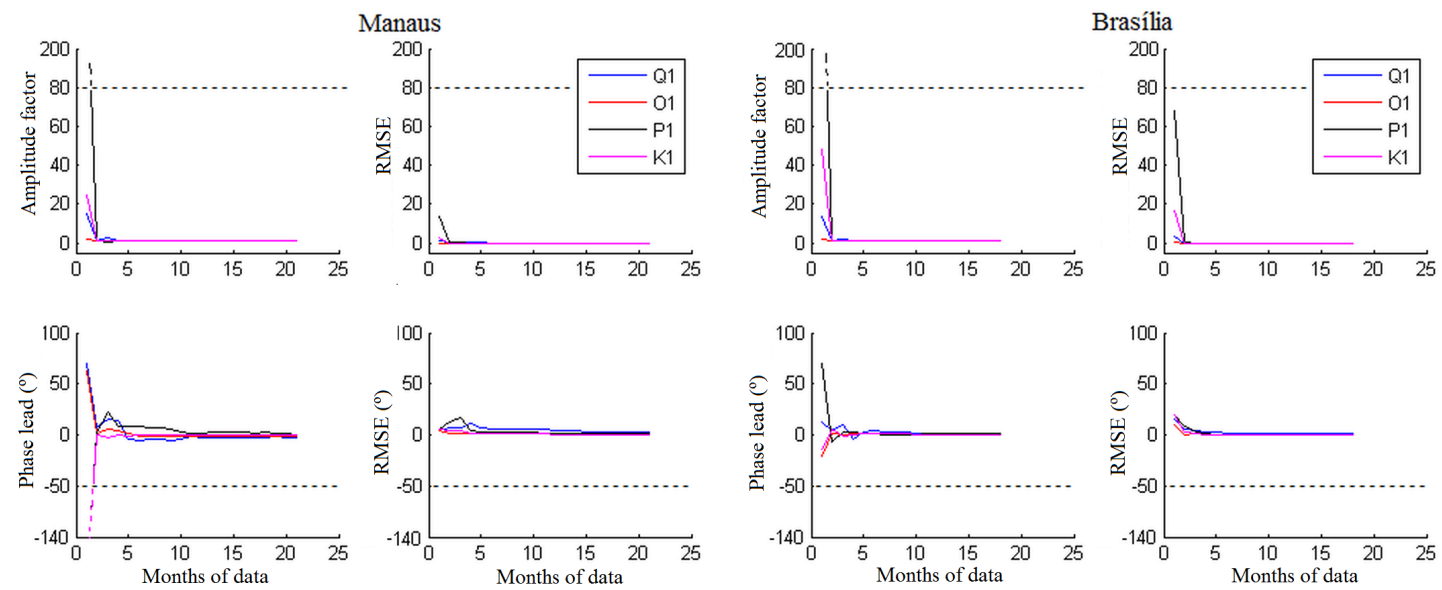

Figure 12 - Amplitude factor, phase difference, and respective RMSE estimated for the diurnal $\left(Q_{1}, O_{1}, P_{1}\right.$, and $\left.K_{1}\right)$ constituents of the Manaus (left) and Brasilia (right) stations. Dotted lines show the change of scale on figure to represent amplitude factor and phase difference. 

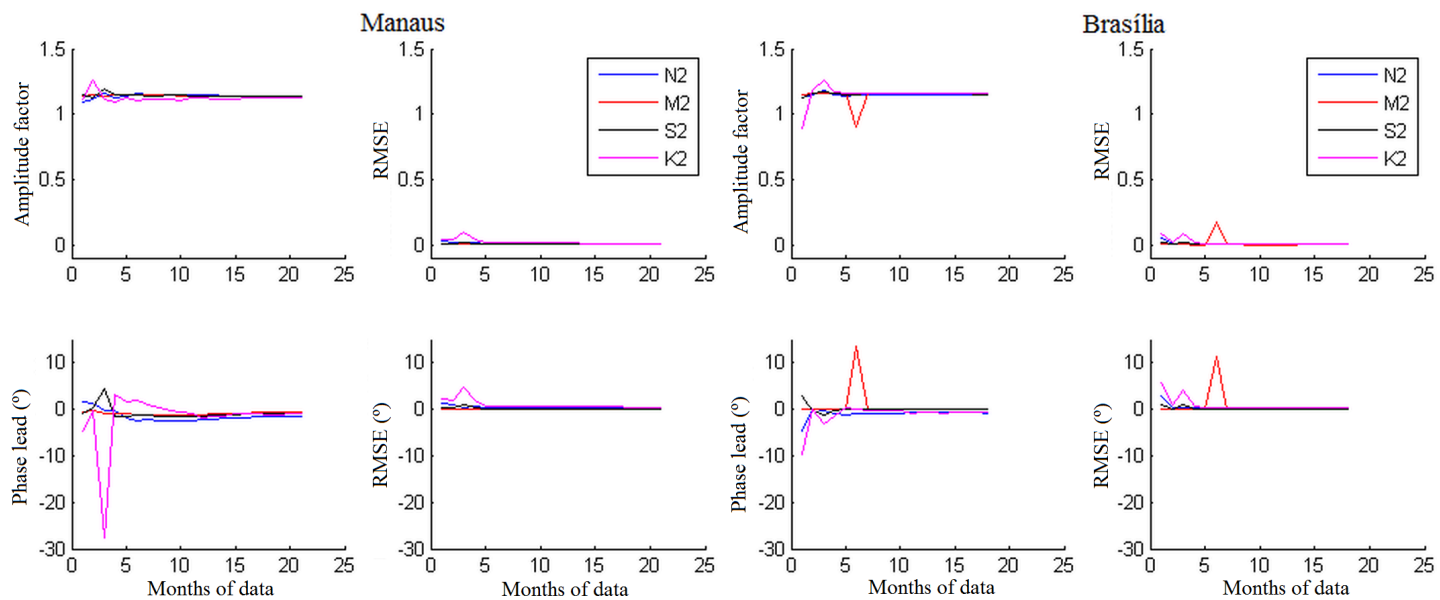

Figure 13 - Amplitude factor, phase difference, and respective RMSE estimated for the semidiurnal $\left(N_{2}, M_{2}, S_{2}\right.$, and $\left.K_{2}\right)$ constituents of the Manaus (left) and Brasília (right) stations.

In the case of phase differences, the diurnal constituents converged after 5 months, in both stations. The RMSE of the phase differences of the Manaus station indicated a better convergence after 14 months.

- For the semidiurnal constituents $\left(N_{2}, M_{2}, S_{2}\right.$, and $\left.K_{2}\right)$ shown in Figure 13, the amplitude factor and the RMSE presented a good fit from the $2^{\text {nd }}$ month, in both stations. The calculated phase differences show convergence after 4 months in the Manaus station, except for the $K_{2}$ constituent, which varied more and began to converge after 9 months. In the Brasilia station, the estimated phase differences converge after 5 months while the $M_{2}$ constituent behaves atypically in the $6^{\text {th }}$ month but returns to the convergence line in the subsequent month. Similar behavior was also observed in the amplitude factor of the $M_{2}$ constituent, it was concluded that possibly some problem might have caused interference in the constituent frequency.

Tables 2 and 3 show the values of the amplitude factor $(\delta)$, phase difference $(\alpha)$, and their respective root mean squared errors (RMSE), for each tide constituent calculated for the Manaus and Brasília stations, respectively. The theoretical amplitude (At) is obtained from the rigid inelastic model of Wahr-Dehant (Dehant, 1987), for a planet without oceans, and the amplitude factor is given by the ratio between the measured amplitudes and those obtained from the rigid inelastic model, according to the local geographic coordinates Costa et al. (2012).
Tables 2 and 3 show that the long period constituent $\left(\mathrm{S}_{s a}\right)$ could be precisely defined. As mentioned previously, this result stems from the short time series available to determine the constituent since the Manaus and Brasília data series were collected over a period of 21 and 18 months, respectively. Therefore, only one full annual cycle was available becoming impossible to obtain redundancy in the observations.

On the other hand, the amplitude factor of the monthly $\mathrm{M}_{m}$ and $\mathrm{M}_{f}$ constituents was well estimated, but a longer time series is also necessary for determining the phase more precisely. This is evident, especially for the Brasília station since the values of phase difference and the respective RMSE of these constituents were high.

The other diurnal and semidiurnal constituents were well estimated, except for the $Q_{1}$ constituent in the Manaus station, which had higher phase difference and RMSE compared to other diurnal constituents.

Figure 14 shows the graphs for the calculated and theoretical tide signals, and the residual resulting from the subtraction of the tide signals from the Manaus and Brasillia stations.

The determined monthly, diurnal and semidiurnal constituents were used for reconstructing the calculated tide signal. The long-period tide $\left(\mathrm{S}_{s a}\right)$ constituent was not included since its results were not satisfactory.

The theoretical tide signal was generated using the same constituents employed for constructing the calculated signal.

The difference between the calculated and the theoretical models, in absolute values, was below 180 and $130 \mathrm{~nm} / \mathrm{s}^{2}$ for 
Table 2 - Solid Earth tide parameters and RMSE estimated from the time data series covering 21 months from the Manaus station, where $\delta$ is the amplitude factor and $\alpha$ is the phase difference.

\begin{tabular}{|c|c|c|c|c|c|}
\hline Wave & At $\left(\mathrm{nm} / \mathrm{s}^{2}\right)$ & $\delta$ & RMSE & $\alpha\left(^{\circ}\right)$ & RMSE $\left(^{\circ}\right)$ \\
\hline $\mathrm{S}_{s a}$ & 31.8501 & 2.1818 & 0.4219 & -15.3164 & 11.0136 \\
\hline $\mathrm{M}_{m}$ & 33.0586 & 1.0781 & 0.0503 & -1.0864 & 2.6786 \\
\hline $\mathrm{M}_{f}$ & 68.5361 & 1.1739 & 0.0220 & 2.6360 & 1.0778 \\
\hline $\mathrm{Q}_{1}$ & 6.4742 & 1.0816 & 0.0454 & -3.2291 & 2.4022 \\
\hline $\mathrm{O}_{1}$ & 33.8560 & 1.1290 & 0.0105 & -1.6805 & 0.5309 \\
\hline $\mathrm{P}_{1}$ & 15.7176 & 1.0813 & 0.0180 & 0.5982 & 0.9531 \\
\hline $\mathrm{K}_{1}$ & 47.1243 & 1.0918 & 0.0067 & 0.4292 & 0.3522 \\
\hline $\mathrm{N}_{2}$ & 143.0996 & 1.1380 & 0.0042 & -1.4821 & 0.2134 \\
\hline $\mathrm{M}_{2}$ & 747.7105 & 1.1391 & 0.0008 & -0.5758 & 0.0408 \\
\hline $\mathrm{S}_{2}$ & 347.5228 & 1.1379 & 0.0018 & -0.8447 & 0.0916 \\
\hline $\mathrm{K}_{2}$ & 101.0867 & 1.1223 & 0.0087 & -0.7401 & 0.4428 \\
\hline
\end{tabular}

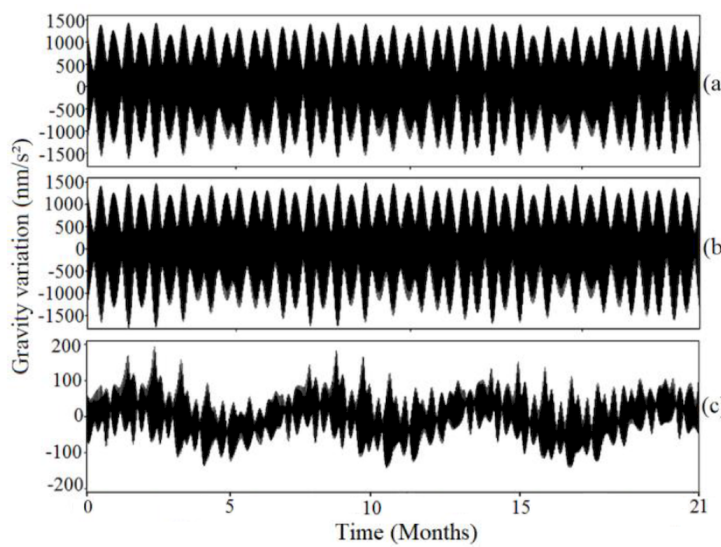

Table 3 - Solid Earth tide parameters and RMSE estimated from the time data series covering 18 months from the Brasilia station, where $\delta$ is the amplitude factor and $\alpha$ is the phase difference.

\begin{tabular}{|c|c|c|c|c|c|}
\hline Wave & At $\left(\mathrm{nm} / \mathrm{s}^{2}\right)$ & $\delta$ & RMSE & $\alpha\left(^{\circ}\right)$ & RMSE $\left(^{\circ}\right)$ \\
\hline $\mathrm{S}_{s a}$ & 25.0458 & 3.8773 & 1.8887 & 0.2638 & 27.5354 \\
\hline $\mathrm{M}_{m}$ & 25.9961 & 1.1029 & 0.2454 & -15.0626 & 12.7522 \\
\hline $\mathrm{M}_{f}$ & 53.8944 & 1.0294 & 0.0965 & 7.7549 & 5.3717 \\
\hline $\mathrm{Q}_{1}$ & 32.1543 & 1.1367 & 0.0364 & -0.1024 & 1.8369 \\
\hline $\mathrm{O}_{1}$ & 168.1466 & 1.1444 & 0.0071 & -0.0799 & 0.3576 \\
\hline $\mathrm{P}_{1}$ & 78.0620 & 1.1227 & 0.0127 & 0.7165 & 0.6468 \\
\hline $\mathrm{K}_{1}$ & 234.0442 & 1.1220 & 0.0047 & 0.2830 & 0.2397 \\
\hline $\mathrm{N}_{2}$ & 132.9573 & 1.1485 & 0.0050 & -0.7581 & 0.2507 \\
\hline $\mathrm{M}_{2}$ & 694.7159 & 1.1560 & 0.0009 & 0.0881 & 0.0467 \\
\hline $\mathrm{S}_{2}$ & 322.8918 & 1.1525 & 0.0021 & 0.0332 & 0.1048 \\
\hline $\mathrm{K}_{2}$ & 93.9221 & 1.1540 & 0.0099 & -0.5257 & 0.4925 \\
\hline
\end{tabular}

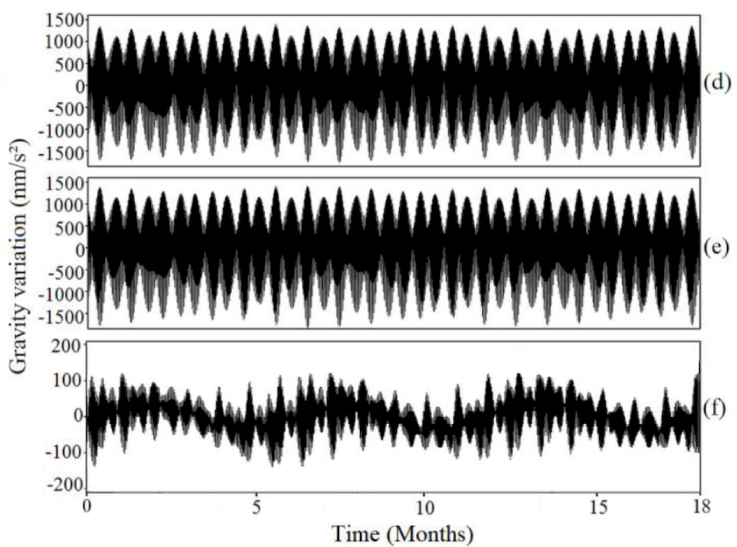

Figure 14 - Tide and residual signals found in the gPhone analysis. The graph on the left shows (a) the calculated tide signal, (b) the theoretical tide signal, and (c) the difference between the calculated and theoretical signals for the Manaus station. The graph on the right shows (d) the calculated tide signal, (e) the theoretical tide signal, and (f) the difference between the calculated and theoretical signals for the Brasilia station.

the Manaus and Brasilia stations, respectively. This difference is explained by the fact that the computed model allows considering local variations that cannot be quantified precisely by the theoretical model.

The difference between the calculated and theoretical tide signals allows identifying variations of frequency, phase and amplitude. Also, allows identifying a seasonal behavior in both stations, possibly caused largely by the hydrological load. However, to reach a more conclusive answer, it is recommended to conduct studies to investigate this phenomenon further in both sites.

\section{Determining Solid Earth Tide Constituents using GNSS Observations}

The GNSS data were treated, processed and the constituents of solid Earth tide were estimated following the methodology presented in section "Positioning Data Editing, Correcting and Processing".

Firstly, the RINEX files for the NAUS and BRAZ stations were edited and standardized. Subsequently, the information regarding the station name, equipment nomenclature and antenna height present in the file header were verified. In addition, the integrity 
of the RINEX files was analyzed using the TEQC program to ensure a problem-free processing.

Initially, to determine the geodetic coordinates, the processing was done using the PPP method in the static mode (Monico, 2007), necessary to solve the ambiguities and to estimate the tropospheric correction parameters to be applied in the kinematic processing.

The kinematic processing was set to determine a coordinate every 3600 seconds (1 hour), so that it became possible to evaluate the displacements suffered by the station over time and to analyze the behavior of the altimetric and planimetric components, aiming at extracting information related to solid Earth tide.

The orbit, clock, and antenna phase center (APC) correction files used in the processing were provided by JPL (Jet Propulsion Laboratory) managed by NASA (National Aeronautics and Space Administration). This work used non-fiducial orbits in the processing. According to Blewitt et al. (1992) non-fiducial orbits do not suffer from reference frame errors.

It is noteworthy that, although the GNSS stations have a long historical data series, the calculations included only the data from the same period of the gPhone, to allow comparing the performance of both methods for determining the solid Earth tide constituents.

In addition, the GLONASS, Galileo, and Beidou observations were discarded because the used version 6.4 of the GIPSY/OASIS (GNSS Inferred Positioning System and
Orbit Analysis Simulation Software) was able to process only observable GPS.

Table 4 shows the strategy used to determine the GPS coordinates.

After GPS processing, the first calculated coordinate was defined as a reference, subtracted from all subsequent coordinates, so that only the positional variation along the time series was represented. Figure 15 shows the signal processed for the NAUS and BRAZ GPS stations of the constituents East $(e)$, North $(n)$ and Up $(u)$.

The graphs (Fig. 15) are on the same scale to facilitate visualizing the stations undergoing greater altimetric movement compared to planimetric. The signals presented below were used for estimating the solid Earth tide constituents.

The values of the displacement velocity vectors of the NAUS and BRAZ stations were inserted before the tidal constituents estimation to adjust the stations coordinates over time.

The amplitudes and phases of the 11 principal solid Earth tide constituents were calculated using the Tidal Fitting Toolbox developed in MATLAB by Aslak Grinsted of the University of Copenhagen

The solid Earth tide constituents estimated by GPS followed the same standard set for gPhone. We started by processing the data of one month, adding the subsequent months one by one, and performing new processing for each month added, thus allowing to follow the convergence of the amplitude and phase values along the analyzed time series.

Table 4 - Solid Earth tide parameters and RMSE estimated from the time data series covering 18 months from the Brasilia station, where $\delta$ is the amplitude factor and $\alpha$ is the phase difference.

\begin{tabular}{|c|c|c|}
\hline Site & Manaus & Brasilia \\
\hline Position (Lat.; Long.; $h)$ & $\begin{array}{c}-03^{\circ} 01^{\prime} \quad 22.5^{\prime \prime} ;-60^{\circ} \quad 03^{\prime} \quad 18.1^{\prime \prime} ; \\
93.89 \mathrm{~m}\end{array}$ & $\begin{array}{c}-15^{\circ} \quad 56^{\prime} \quad 50.9^{\prime \prime} ;-47^{\circ} \quad 52^{\prime} \quad 40.3^{\prime \prime} ; \\
1106.02 \mathrm{~m}\end{array}$ \\
\hline Observation period & $01 / 26 / 2016$ to $11 / 01 / 2017$ & $04 / 25 / 2016$ to $11 / 11 / 2017$ \\
\hline Processing interval & IONEX (Ionosphere Exchange) \\
\hline 2 $^{\text {nd }}$ order ionosphere correction & Vienna Mapping Function (VMF) \\
\hline Troposphere mapping function & JPL (Jet Propulsion Laboratory) \\
\hline Orbit, clock and antenna phase center corrections & FES2004 \\
\hline Ocean load correction & Not applied \\
\hline Solid Earth tide correction & ITRF2008 (IGb08 orbits) \\
\hline Reference frame & I hour) \\
\hline
\end{tabular}



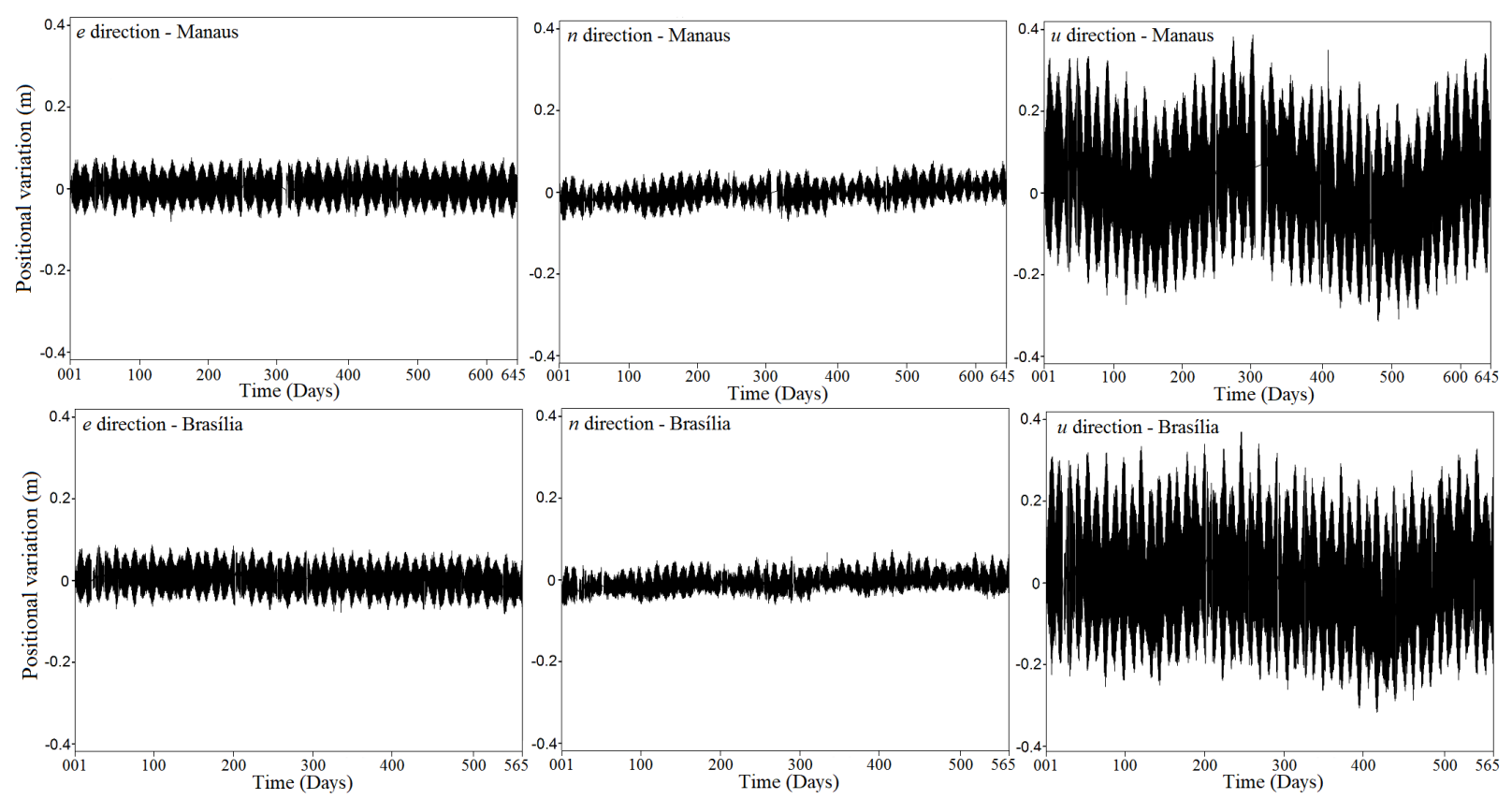

Figure 15 - GPS time series, the three graphs above refer to $e, n$ and $u$ directions of the Manaus station and the three graphs below refer to $e, n$ and $u$ directions of the Brasília station.

The amplitude and phase behavior determined for the long period $\left(\mathrm{S}_{s a}\right)$, monthly $\left(\mathrm{M}_{m}\right.$ and $\left.\mathrm{M}_{f}\right)$, diurnal $\left(\mathrm{Q}_{1}, \mathrm{O}_{1}, \mathrm{P}_{1}\right.$, and $\left.K_{1}\right)$ and semidiurnal $\left(N_{2}, M_{2}, S_{2}\right.$ and $\left.K_{2}\right)$ constituents for the components East, North, and Up of the Manaus and Brasilia stations can be seen in Figures 16, 17, 18 and 19.

The solid Earth tide constituents were not estimated individually by GPS, therefore, it was not possible to estimate the standard deviation of the computed amplitudes and phases.

A careful analysis of Figures 16, 17, 18 and 19 allows inferring the following:

- The long period constituent $S_{s a}$ (Fig. 16) did not have satisfactory results for both stations. As stated earlier, this constituent requires a longer observation period to be determined with high precision;

- In both stations, the monthly constituents $\mathrm{M}_{m}$ and $\mathrm{M}_{f}$ (Fig. 17) show amplitude values converging from the $7^{\text {th }}$ and $4^{\text {th }}$ months for the $e$ and $n$ positions, respectively. On the other hand, the $u$ component showed a greater dispersion but started to converge from the $14^{\text {th }}$ month. The estimated phases for the two stations begin to converge between the $5^{\text {th }}$ and $10^{\text {th }}$ months, depending on the component but dispersed throughout the analyzed series. Possibly, a longer observation series could lead to more consistent results;
- The diurnal constituents $\left(Q_{1}, O_{1}, P_{1}\right.$, and $\left.K_{1}\right)$ shown in Figure 18 indicate that the amplitude begins to converge from the $2^{\text {nd }}$ month, a similar behavior was observed for the positional components of the two stations. The phases of the diurnal constituents converge between the $2^{\text {nd }}$ and $5^{\text {th }}$ months, but some results were not satisfactory. A longer historical series would be important to verify whether there is an improvement when determining the phase of these constituents;

- The results for the semidiurnal constituents $\left(N_{2}, M_{2}\right.$, $\mathrm{S}_{2}$, and $\mathrm{K}_{2}$ ) are shown in Figure 19. The amplitude values show a good adjustment from the $2^{\text {nd }}$ month for both stations. The estimated phases show convergence between the $3^{\text {rd }}$ and $10^{\text {th }}$ months, except for the $K_{2}$ constituent, which showed a sudden behavior change for the $n$ component in the Manaus station, and started to converge from the $17^{\text {th }}$ month. Similar to the diurnal constituents, some phases have not been well determined, and it is understood that a larger historical series would allow determining the phases with higher precision.

Tables 5 and 6 show the calculated amplitude (A) and phase (F) values for the 11 principal tidal constituents determined for each of the positional components and for the NAUS and BRAZ stations, respectively. 

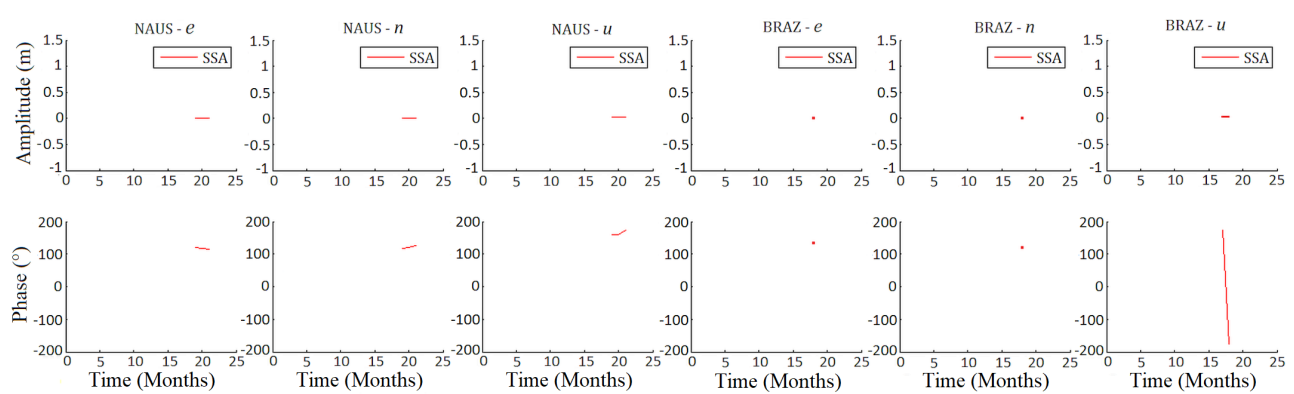

Figure 16 - Amplitudes and phases estimated for the annual constituent $\left(\mathrm{S}_{s} a\right)$, for the East $(e)$, North $(n)$ and Up $(u)$ positions of the Manaus and Brasília stations.
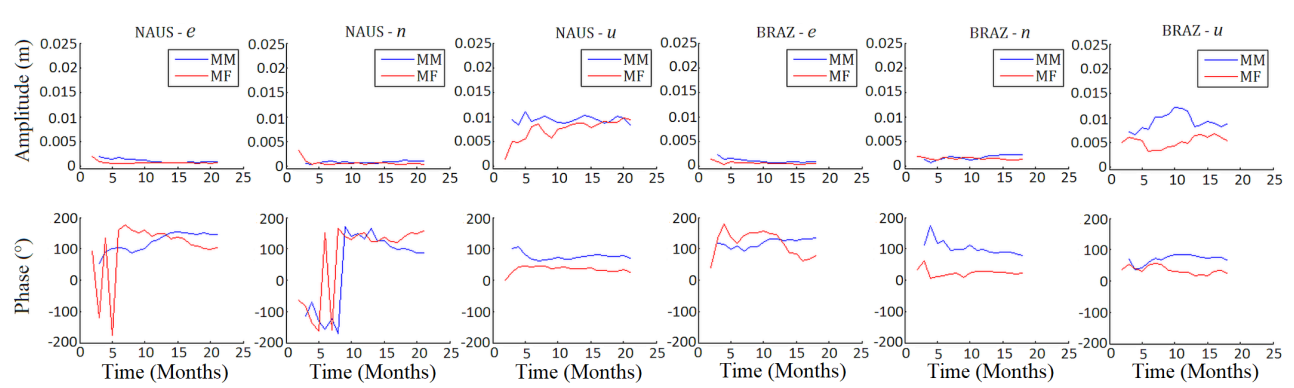

Figure 17 - Amplitudes and phases estimated for the monthly constituents $\left(\mathrm{M}_{m}\right.$ and $\left.\mathrm{M}_{f}\right)$ for the East $(e)$, North $(n)$ and Up $(u)$ positions of the Manaus and Brasília stations.
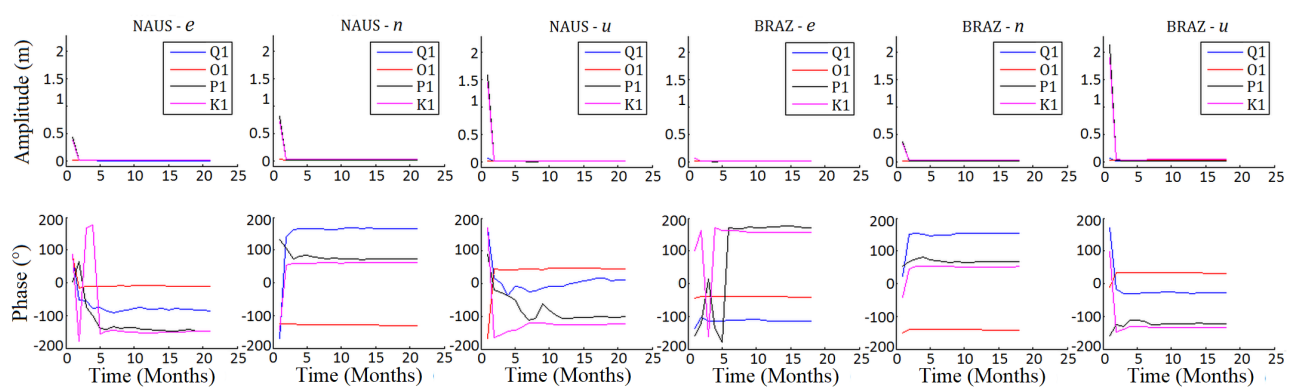

Figure 18 - Amplitudes and phases estimated for the diurnal constituents $\left(Q_{1}, O_{1}, P_{1}\right.$, and $\left.K_{1}\right)$ for the East $(e)$, North $(n)$ and Up $(u)$ positions of the Manaus and Brasilia stations.
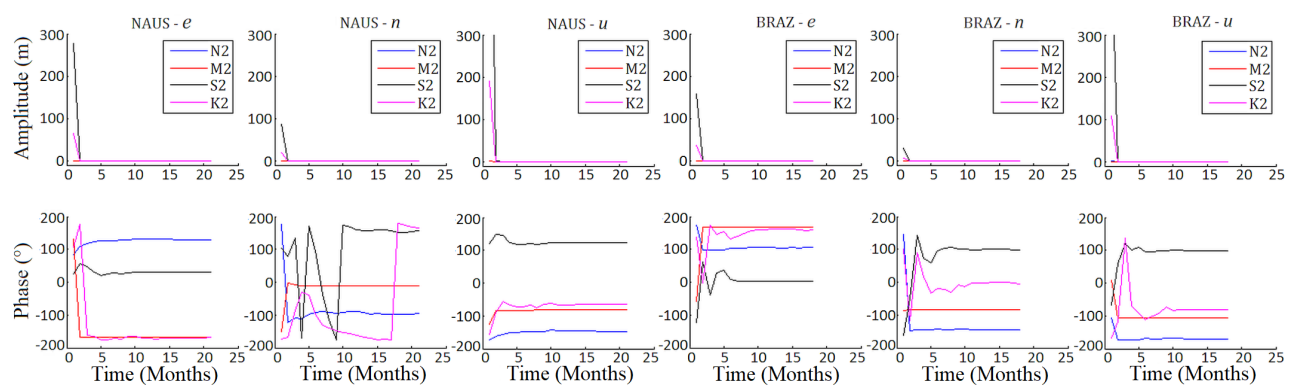

Figure 19 - Amplitudes and phases estimated for the semidiurnal constituents $\left(\mathrm{N}_{2}, \mathrm{M}_{2}, \mathrm{~S}_{2}\right.$, and $\left.\mathrm{K}_{2}\right)$, for the East $(e)$, North $(n)$ and Up $(u)$ position of the Manaus and Brasilia stations. 
Table $\mathbf{5}$ - Solid Earth tide parameters estimated from the time series of positioning data of the NAUS station, where $A$ is the amplitude and $F$ is the phase.

\begin{tabular}{|c|c|c|c|c|c|c|}
\hline Wave & $A(\mathrm{~m})$ & $F\left(^{\circ}\right)$ & $A(\mathrm{~m})$ & $F\left(^{\circ}\right)$ & $A(\mathrm{~m})$ & $F\left(^{\circ}\right)$ \\
\hline & $(e$ direction $)$ & $(e$ direction $)$ & $(n$ direction $)$ & $(n$ direction $)$ & $(u$ direction $)$ & $(u$ direction $)$ \\
\hline $\mathrm{S}_{s} a$ & 0.0013 & 113.86 & 0.0018 & 126.62 & 0.0227 & 172.98 \\
\hline $\mathrm{M}_{m}$ & 0.0009 & 146.13 & 0.0010 & 87.74 & 0.0083 & 69.17 \\
\hline $\mathrm{M}_{f}$ & 0.0007 & 104.38 & 0.0004 & 155.72 & 0.0094 & 26.03 \\
\hline $\mathrm{Q}_{1}$ & 0.0006 & -86.17 & 0.0030 & 163.80 & 0.0011 & 9.82 \\
\hline $\mathrm{O}_{1}$ & 0.0024 & -11.33 & 0.0156 & -131.10 & 0.0048 & 45.04 \\
\hline $\mathrm{P}_{1}$ & 0.0010 & -148.51 & 0.0084 & 72.62 & 0.0017 & -101.18 \\
\hline $\mathrm{K}_{1}$ & 0.0033 & -147.04 & 0.0241 & 61.20 & 0.0062 & -123.22 \\
\hline $\mathrm{N}_{2}$ & 0.0074 & 128.99 & 0.0006 & -95.89 & 0.0284 & -146.95 \\
\hline $\mathrm{M}_{2}$ & 0.0378 & -167.26 & 0.0026 & -11.24 & 0.1478 & -81.92 \\
\hline $\mathrm{S}_{2}$ & 0.0168 & 30.58 & 0.0004 & 155.60 & 0.0687 & 122.87 \\
\hline $\mathrm{K}_{2}$ & 0.0026 & -168.61 & 0.0004 & 165.65 & 0.0120 & -63.10 \\
\hline
\end{tabular}

Table $\mathbf{6}$ - Solid Earth tide parameters estimated from the time series of positioning data of the BRAZ station, where $A$ is the amplitude and $F$ is the phase.

\begin{tabular}{|c|c|c|c|c|c|c|}
\hline Wave & $A(\mathrm{~m})$ & $F\left(^{\circ}\right)$ & $A(\mathrm{~m})$ & $F\left(^{\circ}\right)$ & $A(\mathrm{~m})$ & $F\left(^{\circ}\right)$ \\
\hline & $(e$ direction) & $(e$ direction) & $(n$ direction) & $(n$ direction) & $(u$ direction $)$ & $(u$ direction $)$ \\
\hline $\mathrm{S}_{s} a$ & 0.0025 & 134.88 & 0.0018 & 120.90 & 0.0198 & -175.09 \\
\hline $\mathrm{M}_{m}$ & 0.0008 & 134.32 & 0.0023 & 79.57 & 0.0088 & 66.15 \\
\hline $\mathrm{M}_{f}$ & 0.0005 & 78.53 & 0.0013 & 22.10 & 0.0053 & 25.17 \\
\hline $\mathrm{Q}_{1}$ & 0.0012 & -115.42 & 0.0023 & 154.91 & 0.0053 & -28.89 \\
\hline $\mathrm{O}_{1}$ & 0.0050 & -41.30 & 0.0130 & -142.22 & 0.0270 & 31.60 \\
\hline $\mathrm{P}_{1}$ & 0.0023 & 171.68 & 0.0071 & 66.59 & 0.0141 & -123.00 \\
\hline $\mathrm{K}_{1}$ & 0.0067 & 157.16 & 0.0205 & 51.82 & 0.0357 & -133.00 \\
\hline $\mathrm{N}_{2}$ & 0.0068 & 105.14 & 0.0020 & -145.43 & 0.0260 & -169.29 \\
\hline $\mathrm{M}_{2}$ & 0.0360 & 167.29 & 0.0093 & -82.81 & 0.1386 & -106.45 \\
\hline $\mathrm{S}_{2}$ & 0.0155 & 3.80 & 0.0036 & 98.88 & 0.0609 & 99.06 \\
\hline $\mathrm{K}_{2}$ & 0.0038 & 159.16 & 0.0006 & -6.64 & 0.0109 & -80.12 \\
\hline
\end{tabular}



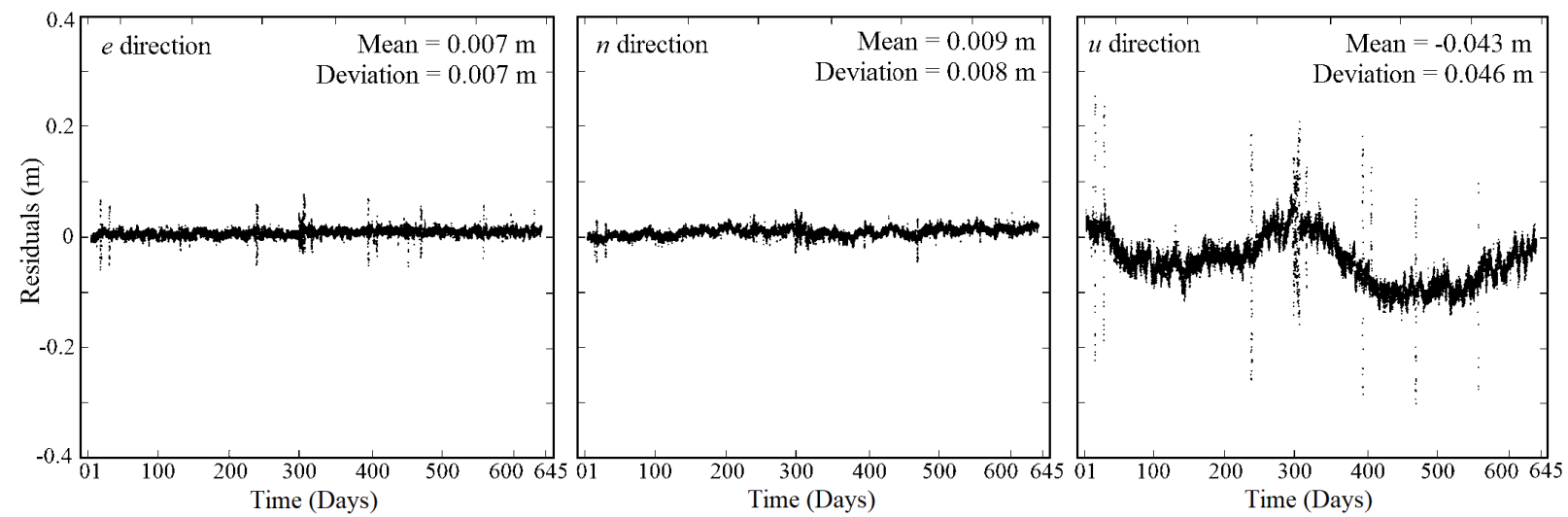

Figure $\mathbf{2 0}$ - Residual difference between the observed and adjusted signals, after applying the estimated solid Earth tide correction, to the $e, n$ and $u$ directions of the Manaus station.
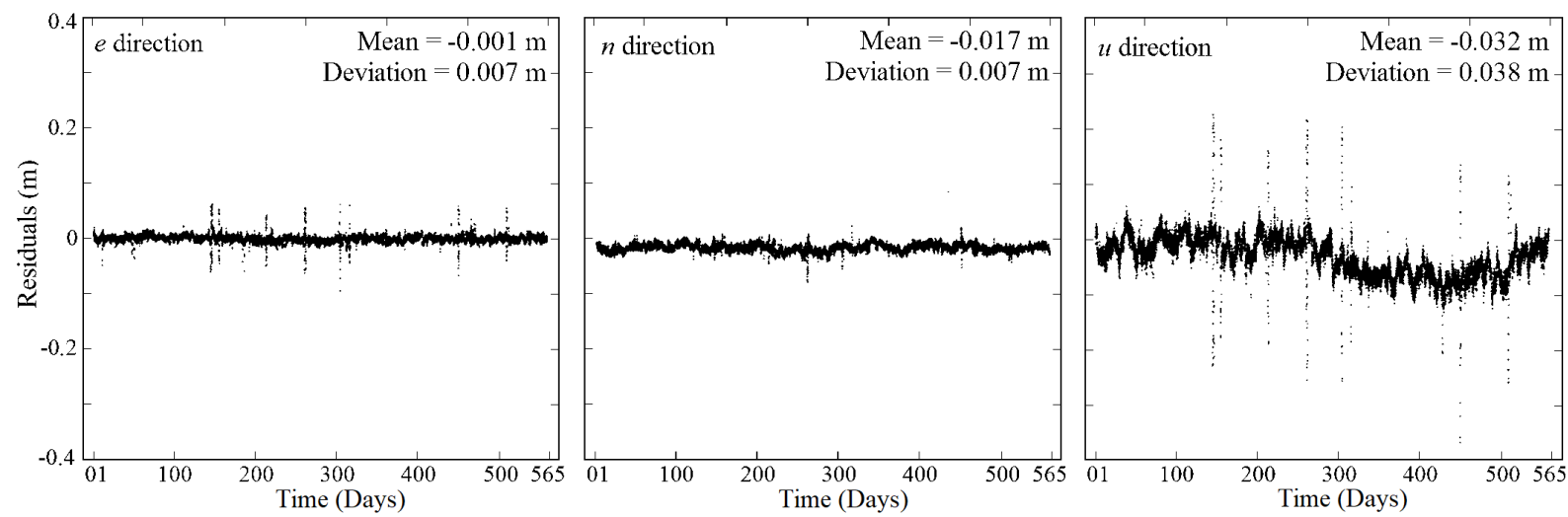

Figure 21 - Residual difference between the observed and adjusted signals, after applying the estimated solid Earth tide correction, to the $e, n$ and $u$ directions of the Brasilia station.

Tables 5 and 6 show that the effect of the vertical component $(u)$ of the solid Earth tide is greater than the horizontal components $(e$ and $n)$. This result stems from the fact that the Earth deformation, related to the tidal force, has a greater effect on the altimetric compared to the planimetric component. It is also seen that some estimated phases had negative values, a result that requires further and more accurate investigation.

Figures 20 and 21 show the residue plots that resulted from the difference between the observed and adjusted signals.

The adjusted signal was generated by applying the correction values of the solid Earth tide constituents estimated in this work to the observed signal.

The analysis of Figures 20 and 21 shows clearly that the residuals in the $u$ direction have a cyclical behavior in both stations. This may be related to some other phenomena, such as hydrological load, atmospheric load and other unmodified effects of smaller magnitude.

\section{CONCLUSIONS}

This paper presents a methodology for estimating the amplitude and phase values of the principal constituents of the solid Earth tide at Manaus and Brasilia, using the gPhone and GPS data. Given the results presented in this paper, some conclusions and recommendations can be presented.

The analysis of the generated data indicated that for the analyzed period, the solid Earth tide constituents were estimated better by the gravimetric data compared to positioning data, especially when determining the phases of the considered constituents. Clearly, a larger historical GPS series should be used for determining these constituents more accurately. 
The residual graphs obtained from the processing of the gPhone and GPS data show a cyclical behavior, which may be related to non-modeled effects that may cause greater uncertainty when determining the solid Earth tide constituents. The hydrological load cycle is one of the effects that was not modeled and has great influence on the observations; however, due to the difficulty in measuring this effect, it still does not have a satisfactory modeling to be applied to high precision geophysical and geodetic observations.

In the light of what has been exposed in this article, it is recommended to continue the analysis using GPS observations to obtain results that could be more conclusive, especially regarding estimations of the long-term constituents of the determined phase values for the solid Earth tide constituents, and cyclical effects.

\section{ACKNOWLEDGMENTS}

The authors thank IBGE and EPUSP for providing geodetic and gravimetric data, and CNPq (460443/2014-3), FAPDF (0193.001230/2016), INCT-ET and CPRM for financial support.

\section{REFERENCES}

AGNEW D. 2010. Earth Tides. In: HERRING T (Ed.). Treatise on Geophysics, Volume 3: Geodesy, p. 163-195.

ALIHAN NSA, WIJAYA DD, DIN AHM, BRAMANTO B \& OMAR AH. 2017. Spatiotemporal Variations of Earth Tidal Displacement over Peninsular Malaysia based on GPS Observations. In: PRADHAN B (Ed.). Global Civil Engineering Conference (GCEC 2017). Singapore. Springer, p. 809-823. doi: 10.1007/978-981-10-8016-6_59.

ARNOSO J, BENAVENT M, BOS MS, MONTESINOS FG \& VIEIRA R. 2011. Verifying the body tide at the Canary Islands using tidal gravimetry observations. Journal of Geodynamics, 51(5): 358-365.

BAKER TF \& BOS MS. 2003. Validating Earth and ocean tide models using tidal gravity measurements. Geophysical Journal International, 152(2): 468-485.

BENEDITO PMP, ALBARICI FL \& TRABANCO JLA. 2017. Determinação preliminar do modelo de maré terrestre para Presidente Prudente/SP. Revista Brasileira de Geomática, 5(3): 420-432.

BLEWITT G, HEFLIN MB, WEBB FH, LINDQWISTER UJ \& MALLA RP. 1992. Global coordinates with centimeter accuracy in the International Terrestrial Reference Frame using GPS. Geophysical Research Letters, 19(9): 853-856.

BOY JP, GEGOUT P \& HINDERER J. 2002. Reduction of surface gravity data from global atmospheric pressure loading. Geophysical Journal International, 149(2): 534-545.
CHEN L, CHEN JG \& XU QH. 2012. Correlations between solid tides and worldwide earthquakes $M_{S} \geq 7.0$ since 1900. Natural Hazards and Earth System Sciences, 12(3): 587-590.

COCHRAN ES, VIDALE JE \& TANAKA S. 2004. Earth tides can trigger shallow thrust fault earthquakes. Science, 306(5699): 1164-1166.

COSTA SMA, MATOS ACOCD \& BLITZKOW D. 2012. Validation of the land water storage from gravity recovery and climate experiment (GRACE) with gauge data in the Amazon basin. Boletim de Ciências Geodésicas, 18(2): 262-281.

DEHANT V. 1987. Tidal parameters for an inelastic Earth. Physics of the Earth and Planetary Interiors, 49(1-2): 97-116.

EKMAN M. 1993. A concise history of the theories of tides, precession-nutation and polar motion (from antiquity to 1950). Surveys in Geophysics, 14(6): 585-617.

ESTEY LH \& MEERTENS CM. 1999. TEQC: the multi-purpose toolkit for GPS/GLONASS data. GPS Solutions, 3(1): 42-49.

FARRELL WE. 1972. Deformation of the Earth by surface loads. Reviews of Geophysics, 10(3): 761-797.

HARTMANN T \& WENZEL HG. 1995. The HW95 tidal potential catalogue. Geophysical Research Letters, 22(24): 3553-3556.

ITO T, OKUBO M \& SAGIYA T. 2009. High resolution mapping of Earth tide response based on GPS data in Japan. Journal of Geodynamics, 48(3-5): 253-259.

JEKELI J. 2012. Geometric reference systems in geodesy. Division of Geodetic Science School of Earth Sciences. Ohio State University, 209 $\mathrm{pp}$.

KANG K, LI H, PENG P, HAO H \& JIN W. 2011. Seasonal variations in hydrological influences on gravity measurements using gPhones. TAO: Terrestrial, Atmospheric and Oceanic Sciences, 22(2): 157-168. doi: 10.3319/TA0.2010.08.02.01.

KASAHARA J. 2002. Tides, earthquakes, and volcanoes. Science, 297(5580): 348-349.

KRÁSNÁ H, BÖHM J, BÖHM S \& SCHUH H. 2012. Solid Earth Tide Parameters from VLBI Measurements and FCN Analysis. In: BEHREND D \& BAVER KD (Eds.). Seventh General Meeting (GM2012) of the International VLBI Service for Geodesy and Astrometry (IVS). Madrid, Spain, 2012, National Aeronautics and Space Administration, p. 405-409.

LACOSTE MG. 2018. gPhone Gravity Meter. gPhone Brochure. Available on: <http://www.microglacoste.com/pdf/Brochure-gPhone.pdf>. Access on: September 10, 2018.

MELCHIOR P. 1983. The tides of the planet Earth. Oxford: Pergamon Press. 2nd ed., 653 pp.

MELCHIOR P. 2008. Gravimetric measuring techniques. Physical Methods, Instruments and Measurements. EOLSS, 2: 259-290. 
MIDDLEMISS RP, SAMARELLI A, PAUL DJ, HOUGH J, ROWAN S \& HAMMOND GD. 2016. Measurement of the Earth tides with a MEMS gravimeter. Nature, 531(7596): 614-617. doi: 10.1038/nature17397.

MIRANDA SA, ORTIZ C, HERRADA AH \& PACINO MC. 2015. Análisis de la marea terrestre gravimétrica en la estación San Juan (Argentina). Boletim de Ciências Geodésicas, 21(4): 721-729. doi: 10.1590/S198221702015000400042.

MONICO JFG. 2007. Posicionamento pelo GNSS: descrição, fundamentos e aplicações. São Paulo, Brazil: Editora Unesp. 2nd ed., 476 pp.

PETIT G \& LUZUM B. 2010. IERS Conventions. IERS Technical Note n. 36. Frankfurt am Main: Verlag des Bundesamts für Kartographie und Geodäsie. 179 pp.

VAN CAMP M \& VAUTERIN P. 2005. Tsoft: graphical and interactive software for the analysis of time series and Earth tides. Computers \& Geosciences, 31(5): 631-640.

VARGA P \& GRAFAREND E. 2019. Influence of tidal forces on the triggering of seismic events. In: BRAITENBERG C \& ROSSI G (Eds.).
Geodynamics and Earth Tides Observations from Global to Micro Scale, Springer. p. 55-63.

WARBURTON RJ \& GOODKIND JM. 1977. The influence of barometric-pressure variations on gravity. Geophysical Journal International, 48(3): 281-292.

WATSON C, TREGONING P \& COLEMAN R. 2006. Impact of solid Earth tide models on GPS coordinate and tropospheric time series. Geophysical Research Letters, 33(8): 1-4. doi: 10.1029/2005GL025538.

YUAN L. 2009. Determination of tidal displacements using the Global Positioning System. Ph.D. thesis. The Hong Kong Polytechnic University. 203 pp.

YUAN L, CHAO BF, DING X \& ZHONG P. 2013. The tidal displacement field at Earth's surface determined using global GPS observations. Journal of Geophysical Research: Solid Earth, 118(5): 2618-2632.

ZUMBERGE JF, HEFLIN MB, JEFFERSON DC, WATKINS MM \& WEBB FH. 1997. Precise point positioning for the efficient and robust analysis of GPS data from large networks. Journal of Geophysical Research: Solid Earth, 102(B3): 5005-5017. 